\title{
Administração tópica de cloridrato de hidralazina na viabilidade de retalho cutâneo randômico em ratos ${ }^{1}$
}

\author{
Topical administration of hydralazine hydrochloride on the viability of randon skin \\ flaps in rats
}

\author{
Ivaldo Esteves Junior ${ }^{2}$, Igor Bordello Masson ${ }^{3}$, Lydia Masako Ferreira ${ }^{4}$, Richard Eloin Liebano ${ }^{5}$, Cristiano Baldan ${ }^{6}$, \\ Alexandre Cavallieri Gomes ${ }^{7}$ \\ 1. Trabalho do Curso de Fisioterapia da Universidade Paulista (UNIP), Disciplina de Cirurgia Plástica da Universidade \\ Federal de São Paulo - Escola Paulista de Medicina (UNIFESP-EPM). \\ 2. Mestre em Ciências Básicas pelo Programa de Pós-Graduação em Cirurgia Plástica Reparadora UNIFESP-EPM. \\ 3. Graduando em Fisioterapia pela UNIP \\ 4. Professora Livre Docente, Titular e Chefe da disciplina de Cirurgia Plástica do Departamento de Cirurgia da UNIFESP. \\ 5. Doutor em Ciências Básicas pelo Programa de Pós-Graduação em Cirurgia Plástica Reparadora UNIFESP-EPM. \\ 6. Especialista em Reabilitação Motora pela Irmandade de Misericórdia Santa Casa de São Paulo (IMSCSP). \\ 7. Mestre em Fisioterapia pela Universidade Federal de São Carlos (UFSCAR).
}

\section{RESUMO}

Objetivo: Investigar o efeito da administração do cloridrato de hidralazina, por iontoforese, na viabilidade de retalho cutâneo randômico em ratos. Métodos: Sessenta ratos da linhagem Wistar foram distribuídos aleatoriamente em 4 grupos ( $n=15)$, estes animais foram submetidos a retalho cutâneo randômico dorsal, de base cranial, com dimensões de 10X4cm. Os animais do grupo 1 foram utilizados como controle, os do grupo 2 foram submetidos a eletroestimulação com corrente direta 4mA-20’ imediatamente após a técnica operatória e nos dois dias subseqüentes. No grupo 3 simulação de estímulo elétrico com Cloridrato de Hidralazina. No grupo 4 iontoforese com Cloridrato de Hidralazina 4mA-20'. A análise dos resultados foi realizada no sétimo dia pós-operatório e interpretada com o Teste não paramétrico de Kruskal-Wallis. Resultados: A media da área de necrose foi: grupo 1 = 45\%; grupo $2=39 \%$; grupo $3=46 \%$ e grupo $4=41 \%$, sendo que a análise estatística não evidenciou diferença significante entre os grupos $(p>0,05)$. Conclusão: o Cloridrato de Hidralazina, quando administrado por iontoforese, não é eficaz em aumentar a área de viabilidade de retalho cutâneo randômico em ratos.

Descritores: Retalhos Cirúrgicos. Hidralazina. Iontoforese. Ratos.

\begin{abstract}
Purpose: Assess the effect of hydralazine hydrochloride, for iontophoresis, on the viability of random skin flaps in rats. Methods: Sixty Wistar rats was randonly destributed in 4 groups $(\mathrm{n}=15)$, these animals was submited as randon dorsal skin flaps as cranial base with measure $10 \mathrm{X} 4 \mathrm{~cm}$. The animals from group 1 was utilized as control, in group 2 was submitted to direct current o 4mA-20' immediately after the surgery and on the two subsequent days. In group 3 the stimulation eletric simulation with hydralazine hydrochloride. In group 4 iontophorese with hydralazine hydrochloride 4mA-20'. The analysis of the results was made on the seventh day post operative and interpreted with test non parametric of Kruskal-Wallis. Results: and the necrotic area stayed fixed in: group 1=45\%; group 2=39\%; group 3=46\% and group 4= 41\%, being the statistical analysis did not evedenced any significant. Conclusion: The hydralazine hydrochloride when taken for iontophorese was not efficacious in reduce the necrotic area.
\end{abstract}

Key words: Surgical Flaps. Hydralazine. Iontophorese. Rats.

\section{Introdução}

O fator que exerce maior influencia no desenvolvimento de necrose na porção distal de retalhos cutâneos é o fluxo sanguíneo inadequado, possivelmente por insuficiência arterial, levando a necrose isquemica ${ }^{1,2}$, com isto, algumas pesquisas utilizam-se de agentes farmacológicos e não farmacológicos com o intuito de aumentar a área de viabilidade de retalhos cutaneos ${ }^{2-9}$.
A hidralazina, uma substância derivada da ftalazina, possui mecanismo de ação que ainda não esta totalmente esclarecido. Porém, mesmo sem o total esclarecimento de seu mecanismo de ação, sabemos que esta é um potente vasodilatador direto, provocando relaxamento seletivo da musculatura, atingindo apenas a musculatura lisa arteriolar sem causar relaxamento da musculatura lisa venosa e também não dilatando vasos de grande capacitância ${ }^{10-12}$. A 
iontoforese é o processo pelo qual íons de soluções são transferidos através da pele intacta, usando de correntes elétricas monofásicas, polarizadas e contínuas. O sistema de administração de drogas por iontoforese é usado comumente em experimentos e, estes demonstram resultados significativos, com o aumento de concentração, das substâncias administradas, na pele levando aos resultados almejados ${ }^{9}$. Sendo assim este trabalho teve como objetivo investigar o efeito da administração tópica do Cloridrato de Hidralazina, por iontoforese, na viabilidade do retalho cutâneo randômico em ratos.

\section{Métodos}

Sessenta ratos da linhagem Wistar (Rattus norvegicus: var. albinus, Rodentia, Mammalia), adultos, machos foram utilizados neste estudo. Os animais foram alojados em gaiolas individuais, recebendo ração comercial e água ad libitum. Os animais foram anestesiados com injeção intraperitoneal de Cloridrato de Tiletamina e Cloridrato de Zolazepan (25mg/kg). Colocou-se os animais em superfície plana com os membros em extensão, realizando-se a tricotomia no dorso dos animais. Advindo então a realização do retalho cutâneo randômico com pedículo cranial, respeitando como limites o ângulo inferior da escápula e os ossos da cintura pélvica, seguindo o modelo experimental ${ }^{2,13,14}$, sendo que interpondo a pele e o retalho foi colocada, na mesma posição, uma barreira plástica com as mesmas dimensões do retalho. A síntese foi realizada com pontos simples com fio de náilon monofilamentar 4-0, de um em um cm. ${ }^{2,13,14}$ Após a técnica operatória os animais do grupo 1 submeteram-se a colocação de eletrodos (3,0 x $5,0 \mathrm{~cm}$ ) do aparelho de corrente galvânica (EGF, Carci ${ }^{\circledR}$, São Paulo, Brasil) posicionados na base do retalho (negativo) e no abdome (positivo) do animal, sendo que entre a pele do animal e os eletrodos havia uma almofada de gaze contendo $3 \mathrm{ml}$ de solução fisiológica (SF). Estes permaneceram nesta posição por 20 minutos, porém sem a emissão de qualquer estímulo pelo eletroestimulador. Os animais do grupo 2 foram submetidos aos mesmos procedimentos do grupo 1 porém, os eletrodos emitiram corrente galvânica com amplitude de 4 mA durante 20 minutos. Os animais do grupo 3 também foram submetidos aos mesmos procedimentos realizados nos animais grupo 1 , porém substituindo a SF colocada na gaze sob eletrodo (negativo) situado no dorso do animal por 3ml de Cloridrato de Hidralazina diluído em SF a uma concentração de $0,2 / \mathrm{mg} / \mathrm{ml}$, nestes animais o eletroestimulador não emitiu qualquer estímulo. Os animais do grupo 4 submeteram-se aos mesmos procedimentos do grupo 3, porém estes receberam a estimulação com corrente Galvânica, como citada no grupo 2 (iontoforese). Estes procedimentos repetiram-se por dois dias subseqüentes (PO1 e PO2). A porcentagem da área de necrose dos retalhos foi verificada no sétimo dia após a técnica operatória por meio de gabarito de papel ${ }^{15}$. Estes procedimentos foram realizados em estudo duplo cego. Para interpretação dos resultados foi utilizado o teste não paramétrico de Kruskal Wallis para amostra independente e, complementado, se necessário, pelo teste de comparações múltiplas. O nível de rejeição para hipótese de nulidade foi fixado em $p<0,05$.

\section{Resultados}

A media da porcentagem da área de necrose foi: grupo $1=45$; grupo $2=39$; grupo $3=46$ e grupo $4=40$. O teste de Kruskal-Wallis não evidenciou diferença estatisticamente significante, $(p>0,05), \mathrm{G} 1=\mathrm{G} 2=\mathrm{G} 3=\mathrm{G} 4$.

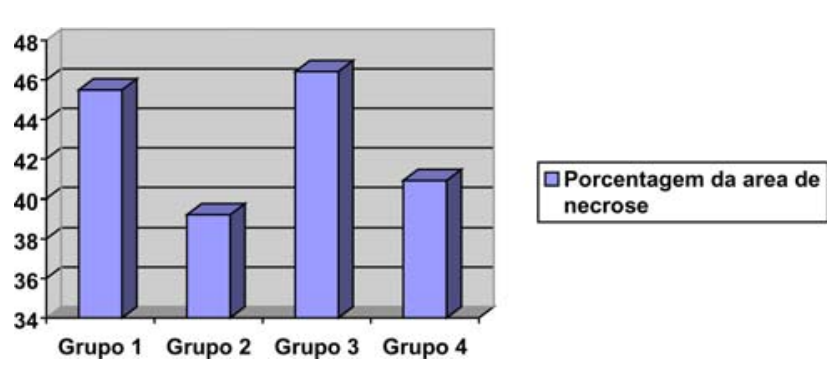

FIGURA 1 - Colunas representando área de necrose do retalho cutâneo: grupo controle (1), grupo iontoforese placebo (2), grupo controle de absorção (3) e grupo tratamento (4).

\section{Discussão}

O presente estudo utilizou o modelo de retalho cutâneo randômico de base cranial proposto por McFarlane et al. ${ }^{16}$ como modelo experimental para se estudar a necrose e a prevenção da mesma. As dimensões usadas neste modelo são de $10 x 4 \mathrm{~cm}$. Para se obter condições homogêneas de necrose foi interposto um filme plástico com as mesmas dimensões do retalho, colocado entre o retalho e o seu leito doador, com o propósito de impedir a revascularização através de vasos do leito doador ${ }^{17,18}$, observando assim uma necrose significativa ${ }^{2,18}$. Estes mesmos procedimentos foram utilizados também por Liebano et al. ${ }^{2}$ e Duarte et al. ${ }^{14}$. A avaliação da porcentagem da área de necrose foi medida pelo método de gabarito de papel descrito inicialmente por Sasaki, Pang ${ }^{15}$, que se deu no sétimo dia pós-operatório, principalmente, por expressar confiabilidade com erro menor que $5 \%$ além de ser facilmente aplicável e amplamente utilizado na literatura. A diferença entre tecido viável e tecido necrótico foi feita após o sacrifício dos animais, com hiperdosagem anestésica, com observação macroscópica sendo que o tecido viável possuía cor rósea, textura macia e crescimento de pêlos diferindo-se do tecido necrótico com pele escurecida, rígida, fria e sem pêlos. Quando eleita a iontoforese como via de administração de uma substância, é preciso atentar-se a alguns fatores importantes. A primeira consideração relaciona-se as características da substância a ser introduzida, pois esta deve de ser ionizada ou ionizável, para que empregue a transmissão de íons entre a pele e a substância. Segundo, sabendo que o mecanismo de aplicação da iontoforese é a repulsão de cargas iguais, é necessário saber qual o comportamento iônico da substância a ser introduzida para que possa ser colocada sobre esta um eletrodo da mesma polaridade para se conseguir a repulsão entre estas cargas iguais, sendo que este eletrodo é colocado na região onde se quer administrar a substancia referida (área alvo). Poucas pesquisas experimentais utilizam-se deste antigo recurso que é a iontoforese. Apenas um trabalho utilizando a iontoforese realizado por Asai et 
al. ${ }^{9}$ este na mesma área de pesquisa experimental que o presente estudo. Asai et al. ${ }^{9}$ utilizaram a iontoforese para a introdução de prostaglandina E1 na investigação de seus efeitos no retalho cutâneo. A hidralazina, substância utilizada no presente estudo, é uma substância não ionizada, mas sim ionizável. Esta foi utilizada em forma de cloridrato, o que a deixa com o comportamento iônico negativo. A hidralazina foi utilizada seguindo modelo observado nos trabalhos de Liebano et al. ${ }^{2}$ e Asai et al. ${ }^{9}$, que realizam técnicas de tratamento em pós-operatório, por acreditar-se que os eventos que se seguem imediatamente após a elevação do retalho irão interferir diretamente em sua área de viabilidade ${ }^{2,14}$. Finseth et al ${ }^{10}$ e Suarez Nieto et al. ${ }^{11} \mathrm{em}$ seus trabalhos utilizam-se de hidralazina, em administrações sistêmicas, em tratamentos que combinam o período pré e pós-operatório e, estes vêm a controlar a necrose em seus modelos satisfatoriamente, porem Toomey et al. ${ }^{12}$ utilizam modelo semelhante sem alcançar os mesmos resultados. Estes trabalhos propõem protocolos de tratamento que variam entre 22 e 14 dias, o que vem a sugerir que os efeitos da hidralazina, possivelmente ligado ao relaxamento da musculatura lisa de arteriolar, apresenta mecanismos de ação cumulativos a sua aplicação logo, não sendo adequado em protocolos que exigem mecanismos de ação rápidos. Novas pesquisas com o cloridrato de hidralazina, por iontoforese, para viabilidade do retalho cutâneo devem seguir-se, utilizando períodos de pré-tratamento em protocolos mais longos.

\section{Conclusäo}

A administração tópica de cloridrato de hidralazina por iontoforese não foi eficaz em aumentar a área de viabilidade do retalho cutâneo randômico em ratos.

\section{Referências}

1. Kerrigan CL. Skin Flap Failure: Pathophysiology. Plast Reconstr Surg. 1983; 72(6): 766-77.

2. Liebano RE, Ferreira LM, Neto MS. The effect of transcutaneous electrical nerve stimulation on the viability of randon skin flaps in rats. Cand J Plast Surg. 2002; 10(4): 151-4.

3. Averbeck B, Reeh PW. Interactions of inflammatory stimulating release of calcitonin gene-related peptide, substance $\mathrm{P}$ and prostaglandin E2 from isolated rat skin.. Neuropharmacology. 2001; 40: 416-23.

4. Gherardini G, Lundebergh T, Cui J, Eriksson SV, Trubek S, Linderoth B. Spinal cord stimulation improves survival in ischemic skin flaps: an experimental study of the possible mediation by calcitonin gene-related peptide.
Plast Reconstr Surg. 1999; 103(4): 1221-8.

5. Ranne JO, Lahteenmaki PT, Vaalasti A, Waris TH, Lindholm TS. Adequate blood flow is essential for reinnervation in neurovascular skin flaps. Scand J Plast Reconstr Hand Surg. 1999; 33: 7-12.

6. Jansen G, Torkvist L, Lofgren O, Rauld J, Lundebergh T. Effects of calcitonin gene-related on tissue survival, blood flow and neutrophil recruitment in experimental skin flaps. Br J Plast Surg. 1999; 52(4): 299-303.

7. Gherardini G, Gurleck A, Milner SM, Matarasso A, Evans GRD, Jernbeck J, Lundebergh T. Calcitonin gene-related peptide improves skin flap survival and tissue inflammation. Neuropeptides. 1998; 32(3): 269-73.

8. Kjartansson J, Lundebergh T, Samuelsson EU, Dalsgaard J, Hedén P. Calcitonin gene-related peptide (CGRP) and transcutaneous electrical nerve stimulation (TENS) increase cutaneous blood flow in a musculocutaneous flap in the rat. Acta Physiol. Scand. 1988; 134(1): 89-94.

9. Asai A, Fukuta K, Torii S. Topical Administration of Prostaglandin E1 with Iontophoresis for Skin Flap Viability. Ann Plast Surg. 1997; 38(5): 514-7.

10. Finsenth F, Adelberg MG. Prevention of skin flap necrosis by a course of treatment with vasodilator drugs. Plast Reconstr Surg. 1978; 61: 738-43.

11. Suarez Nieto C, Suarez Garcia MJ, Barthe Garcia P. A comparative study on the effect of various pharmacological agents on the survival of skin flaps in the rat. Br J Plast Surg. 1992; 45: 113-6.

12. Toomey JM, Conoyer JM, Ogura JH. Vasodilating agents in augmentation of skin flap survival. Otolaryngol Head Neck Surg. 1979; 87: 757-62.

13. Liebano RE, Ferreira LM, Sabino Neto M. Modelo experimental para estimulação elétrica nervosa transcutanea em retalho cutâneo randômico isquêmico em ratos. Acta Cir Bras. 2003; 18: 54-9.

14. Duarte SI, Gomes HF, Ferreira LM. Effect of dimethil sulphoxide on necrosis of skin flaps in rats. Can J Plast Surg. 1996; 6: 93-7.

15. Sasaki GH, Pang CY. Hemodinamics and viability of acute neurovascular island skin flap in rats. Plast Reconstr Surg. 1980; 65: 152-8.

16. McFarlane RM, Deyoung G, Henry RA. The design of a pedicle flap in the rat to study necrosis and its prevention. Plast Reconstr Surg. 1965(2); 35:177-82.

17. Ugland O. Flaps and flap necrosis. Acta Chir Scand. 1966; 131: 408-12.

18. Kaufman T, Angel MF, Eichenlaub EH, Levin M, Hurwitz DJ, Futrell J. The salutary effects of the bed on the survival of experimental flaps. Ann Plast Surg. 1985; 14(1): 64-73.
Correspondência:

Ivaldo Esteves Junior

Rua Cangati, 300

CEP: 05343-070 - Jaguaré - SP

Tel: (11) 3768-5525 / 9633-7141

ivaldofisio@ig.com.br
Conflitos de interesse: nenhum Fonte de finaciamento: nenhuma

Recebimento: 04/10/2004 Revisão: 09/11/2004

Aprovação: 07/12/2004 


\section{Como citar este artigo:}

Esteves Junior I, Masson IB, Ferreira LM, Liebano RE, Baldan C, Gomes AC. Administração tópica de cloridrato de hidralazina na viabilidade de retalho cutâneo randômico em ratos. Acta Cir Bras [serial online] 2005 Mar-Abr; $20(2)$. Disponível em URL: http://www.scielo.br/acb

Figura colorida disponível em http://www.scielo.br/acb 